\title{
Development of the mesendoderm in the dendrobranchiate shrimp Sicyonia ingentis
}

\author{
Philip L. Hertzler* \\ Department of Biology, Central Michigan University, Brooks 217, 100 W. Preston Road, Mt. Pleasant, MI, USA
}

Received 2 February 2002; accepted 5 April 2002

\begin{abstract}
Dendrobranchiate shrimp embryos form a 4-cell stage that resembles spiralians in its cell contacts, but cleavage proceeds radially without any further evidence of spiralian character. The fates of Sicyonia ingentis mesendoblasts were followed by nuclear staining and confocal microscopy. The dorsal mesendoblast produced yolk-endoderm, which proliferated from the anterior of the embryo to cover the dorsal interior. The ventral mesendoblast divided into the primordial endoblast and a cell that further divided into the primordial mesoteloblast and the primordial germ cell. The primordial endoblast divided into left and right endoblasts, which then underwent two teloblastic divisions, leaving behind two pairs of smaller descendants and the larger endoblasts at the dorsal posterior. The endoblasts then paused in cell division while extensive morphogenesis occurred in the ectoderm to form the naupliar segments. Ectoteloblasts formed at the posterior. The primordial mesoteloblast underwent two asymmetric divisions, synchronously with the endoblasts, to form two small descendants and M2 at the ventral posterior. From 15 to 18 h, M2 divided laterally then dorsal-ventrally to form four descendants. The results extend the cell lineage of $S$. ingentis from the egg to the nauplius larva, and demonstrate that endoderm forms dorsal to teloblastic mesoderm from an early stage. (C) 2002 Elsevier Science Ltd. All rights reserved.
\end{abstract}

Keywords: Dendrobranchiata; Sicyonia ingentis; Shrimp; Cell lineage; Mesoteloblasts; Ectoteloblasts

\section{Introduction}

Crustacean development occurs by a bewildering variety of modes, ranging from one extreme of small, freely shed eggs with holoblastic cleavage to a free-swimming nauplius larva to the other extreme of large, maternally brooded eggs with superficial cleavage and release at an advanced larval stage (reviewed by Shiino (1957), Anderson (1973) and Gilbert (1997)). Holoblastic cleavage is typical of many primitive crustacean groups, but only occurs among euphausiid and dendrobranchiate shrimps among the Malacostraca. Euphausiid and dendrobranchiate shrimp develop to a free-swimming nauplius stage with several instars where posterior development occurs. The nauplius larva has three paired appendages (first antennae, second antennae, and mandibles), a post-naupliar rudiment at the posterior, and a single naupliar eye at the anterior. In most malacostracan crustaceans, the naupliar stage is passed while brooded on the female as an egg-nauplius (Scholtz, 2000), or suppressed in association with development

\footnotetext{
* Fax: + 1-989-774-3462.

E-mail address: philip.1.hertzler@cmich.edu (P.L. Hertzler).
}

through more advanced larval stages (Brusca and Brusca, 1990).

Crustacean development is also characterized by teloblastic growth of the posterior part of the body (Gilbert, 1997). Stem cells called ectoteloblasts and mesoteloblasts produce the post-naupliar ectoderm and mesoderm by dividing posteriorly, leaving descendants behind them. Most malacostracans have a characteristic number of teloblasts, 19 ectoteloblasts and eight mesoteloblasts, in a growth zone just anterior to the telson (Scholtz, 2000). The growth zone produces regular rows of descendants that provide the tissue of the post-naupliar segments. In penaeoidean shrimp, the next four segments (first and second maxillae, first and second maxillipeds) develop by the nauplius 5 stage (Dall et al., 1990).

The holoblastic cleavage of euphausiid and dendrobranchiate shrimp allows cell lineages to be followed, as has been done for the krill Euphausia (Taube, 1909, 1915) and dendrobranchiate shrimp Lucifer (Brooks, 1882), Penaeus japonicus (Kajishima, 1951), Penaeus kerathurus (Zilch, 1978, 1979), and Sicyonia ingentis (Hertzler and Clark, 1992; Hertzler et al., 1994) (see Fig. 1 for classification). In these species, several common features of cleavage and 


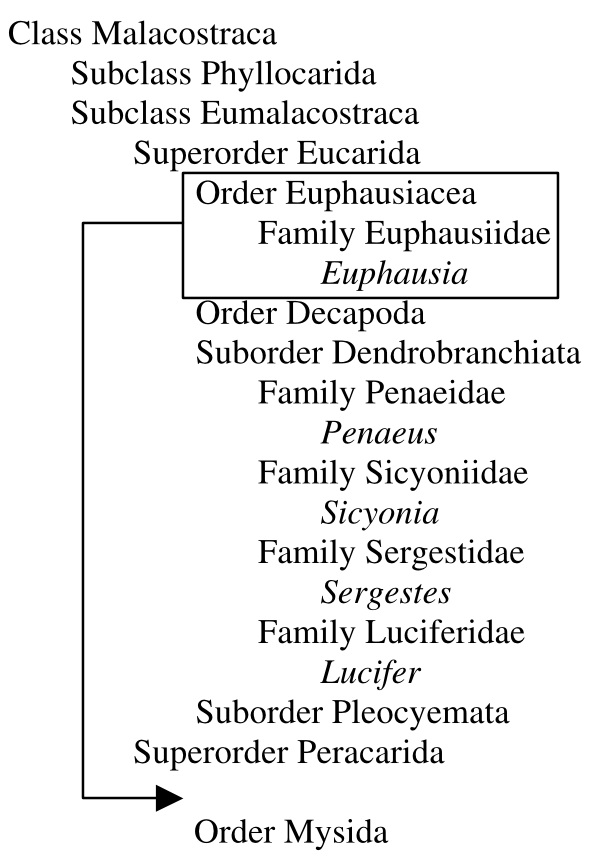

Fig. 1. Revised classification of the Malacostraca including relevant species (Bowman and Abele, 1982; Burkenroad, 1983; Brusca and Brusca, 1990; Jarman et al., 2000; Richter and Scholtz, 2001). Recent studies place the Euphausiacea among Superorder Peracarida, from their previous close relationship to the Dendrobranchiata (Jarman et al., 2000; Richter and Scholtz, 2001). Relationships within the Dendrobranchiata are controversial (Perez-Farfante and Kensley, 1997; Baldwin et al., 1998; Maggioni et al., 2001).

morphogenesis are evident, including radial cleavage after a spiral-type 4-cell stage, the early immigration of two mesendoderm cells inside the blastula, the subsequent invagination of 8-9 prospective naupliar mesoderm cells, and the direct formation of naupliar appendages that are initially uniramous. The first antennae remain uniramous, while the second antennae and mandibles split to become biramous (Scholtz, 2000). The cell lineage is still incomplete for any single penaeoidean species, however, since the earliest cleavage stages (through 16 cells) could not be followed in $P$. kerathurus, while later fates of the mesendoderm were not followed for $S$. ingentis. This study extends the cell lineage for $S$. ingentis by following the mesendoderm cells by nuclear staining to $18 \mathrm{~h}$ post- spawning. In Sicyonia, the dorsal mesendoblast gives rise to yolk-endoderm cells, while the ventral mesendoblast produces the primordial endoblasts, the primordial mesoteloblast, and the primordial germ cell.

\section{Material and methods}

\subsection{Animals and embryos}

Gravid S. ingentis were collected by otter trawl off Palos Verdes, California during the summer of 2001 and transported to Occidental College, Los Angeles, California. Animals were maintained in a 200-gallon flow-through seawater aquarium and induced to spawn as described previously (Pillai et al., 1988). Fertilized eggs were collected in finger bowls containing artificial seawater (ASW), pH 8.2 and $50 \mu \mathrm{M} 3$-amino-2,3,4-triazole to soften hatching envelopes. Embryos were sampled every $15 \mathrm{~min}$ from 5 to $9.25 \mathrm{~h}$ post-spawning, then every one hour to $21 \mathrm{~h}$, stripped of their hatching envelopes with $200 \mu \mathrm{m}$ nylon screen, and fixed and stored in ice-cold 90\% methanol$50 \mathrm{mM}$ EGTA, pH 8.0. Nauplius 1 stages at $24 \mathrm{~h}$ were fixed directly in $90 \%$ methanol-50 mM EGTA, pH 8.0.

\subsection{Nuclear staining and confocal microscopy}

Samples were taken to Central Michigan University, where they were rehydrated in Tris-buffered saline (TBS; $0.9 \% \mathrm{NaCl}-10 \mathrm{mM}$ Tris, $\mathrm{pH} 7.5$ ) and stained for $3 \mathrm{~h}$ with 1:1000 dilution of Sytox Green (Molecular Probes, Inc.) in TBS. Samples were rinsed once with TBS, then dehydrated in three changes of $100 \%$ ethanol and finally cleared and stored in methyl salicylate. Embryos were gently resuspended, a drop was placed on a slide inside an oval of vacuum grease, and a cover slip was carefully placed on the preparation. Staining was observed with an Olympus Fluoview 300 laser scanning confocal microscope, using argon laser excitation with a 20X Plan Apo 0.7 NA or 40X Fluor 0.75 NA objective lens. Representative samples were selected in the desired orientations. Most late-stage embryos rested on their dorsal or ventral sides, yielding frontal sections. To obtain cross-sections or sagittal sections, slides

Fig. 2. S. ingentis development from 6 to $7 \mathrm{~h}$, optical sections of samples stained with either anti- $\beta$-tubulin antibody for microtubules (A) or Sytox Green for DNA (B-L). (A) Composite of several sagittal sections at $6 \mathrm{~h}$, dorsal at the top, anterior to the left. The dorsal mesendoblast descendants are Ya and Yp, while the ventral mesendoblast descendants are MEvp and MEva, the primordial endoblast E. Naupliar mesoderm (NM) forms the invagination to the posterior. (BD) Single transverse sections from $6.25 \mathrm{~h}$ embryo, moving towards the posterior; dorsal at the top. Ya and E can be seen dividing laterally (B), while Yp and MEvp divide in an oblique plane dorsoventrally and anteroposteriorly (C, D). (E-H) Single transverse sections of 6.5 h embryo, dorsal at the top. (E) Posterior cross-section, showing mediolateral spread of naupliar mesoderm $(\mathrm{NM})$. ( $\mathrm{F}-\mathrm{H})$ Transverse sections from anterior to middle of the embryo, showing arrangement of eight mesendodermal descendants. At the anterior, the sisters Yal and Yar are located dorsally, while El and Er are ventral (F). Further posterior, Ypa is dorsal while MEvpa, the primordial mesoteloblast M, is ventral (G). Still further posterior, Ypp and MEvpp, the primordial germ cell PGC, are found (H). (I-L) Single frontal sections from a $7 \mathrm{~h}$ embryo, moving from dorsal to ventral; anterior to left. Ypa and Ypp are most dorsal (I), while Yal and Yar are deeper into the embryo (J). Naupliar mesoderm is present in the posterior invagination. Further ventrally, El and Er are present with large nuclei (K). In ventral sections, M and PGC are present (L). Abbreviations: E, primordial endoblast; M, primordial mesoteloblast; NM, naupliar mesoderm; PGC, primordial germ cell. Scale bar $=50 \mu \mathrm{m}$. 

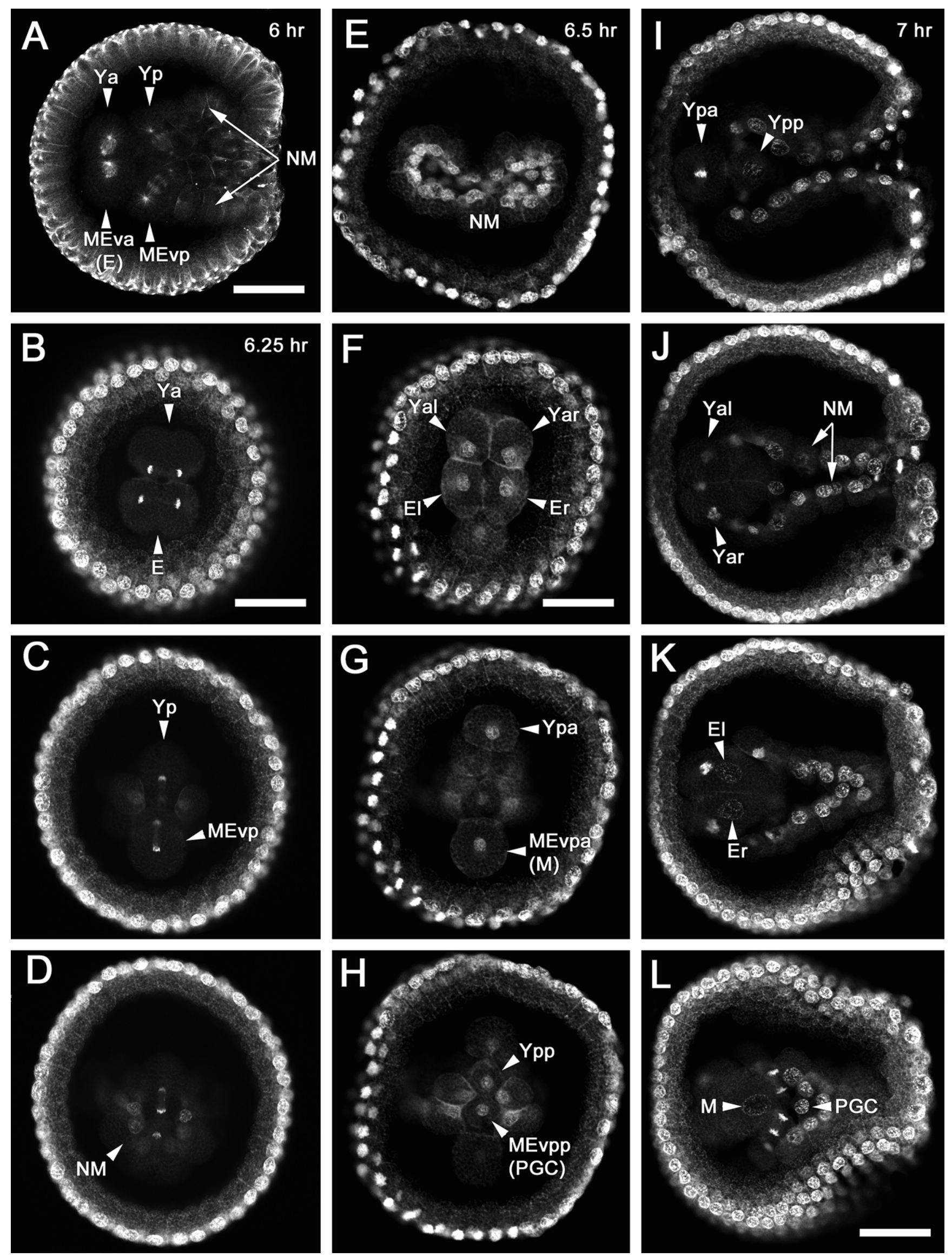
were tipped $90^{\circ}$ and the embryos were allowed to settle against the vacuum grease of the slide preparation. Optical sections were collected at an image size of $1024 \times 1024$ pixels, a digital zoom of $1-2.5 \mathrm{X}$ and medium scan speed $(5.31 \mathrm{~s} / \mathrm{scan})$. Serial sections in the $Z$ plane were collected at 2-3 $\mu \mathrm{m}$ intervals and saved as Olympus multi-TIFF files. Individual images were saved as 24-bit bitmap files for composition into plates using Adobe Photoshop 5.5. Plates were saved in TIFF file format and printed using a Fujix Pictography 3000 printer.

\section{Results}

\subsection{Mesendoderm development from 3.5 to $7 \mathrm{~h}$}

The two mesendoblasts that formed at the 32-cell stage (about $3.5 \mathrm{~h}$ post-spawning) remain undivided for three cell cycles inside the embryo at the anterior end (Hertzler and Clark, 1992). The naupliar mesoderm invaginates after the mesendoblasts, forming a classic invagination gastrula, and is retarded in division relative to the rest of the ectoderm (Hertzler and Clark, 1992, Fig. 3). Although no dorsalventral axis is apparent at this stage, tracing the cells back from later stages reveals that one mesendoblast is dorsal $(\mathrm{MEd}=\mathrm{Y})$ and the other is ventral $(\mathrm{MEv})$. At $5.5 \mathrm{~h}$ postspawning, the two mesendoblasts divide along an anteriorposterior axis to form two anterior and two posterior descendants (Hertzler and Clark, 1992, Fig. 3E). The two dorsal descendants are designated $\mathrm{Ya}$ and $\mathrm{Yp}$, and the two ventral cells are MEva (E) and MEvp; these cells are in metaphase at $6 \mathrm{~h}$ (Fig. 2A). Posterior to the four mesendoblasts, the naupliar mesoderm forms an invagination from the blastopore (Fig. 2A). At $6.25 \mathrm{~h}$, the anterior cells divide laterally to form Yal, Yar, El and Er (Fig. 2B and F). The posterior cells Yp and MEvp divide along an anteriorposterior, slightly oblique cleavage plane (Fig. 2C and D). Yp forms the larger Ypa at the dorsal, anterior (Fig. 2G) and smaller Ypp at the medial, posterior (Fig. 2H), while MEvp forms the larger MEvpa (M) at the ventral, anterior (Fig. 2G) and smaller Mevpp (PGC) at the medial, ventral (Fig. 2H).

The posterior invagination of naupliar mesoderm becomes flattened laterally by $6.5 \mathrm{~h}$ (Fig. 2E), which provides another orienting feature. The eight mesendodermal descendents maintain their relative positions through succeeding divisions, allowing their fates to be traced in later time points. MEval and MEvar are the primordial endoblasts (El and Er), MEvpa is the primordial mesotelo- blast (M), and MEvpp is the primordial germ cell (PGC). The remaining mesendodermal descendents, Yal, Yar, Ypa, and Ypp form the yolk-endoderm cells.

\subsection{Development from 7 to $8 \mathrm{~h}$}

In frontal sections at $7 \mathrm{~h}$, three yolk-endoderm cells (Ypa, Yal, Yar) are in late prophase while the other mesendoderm descendants remain in interphase (Fig. 2I-L). Ypp lies posterior to Ypa in the same section plane (Fig. 2I), while Yal and Yar lie ventrally to them (Fig. 2J). The primordial endoblasts El and Er are ventral to Yal and Yar and remain in interphase with large nuclei (Fig. 2K). The primordial mesoteloblast $(\mathrm{M})$ remains in interphase along the ventral ectoderm (Fig. 2L). The primordial germ cell (PGC) also remains in interphase, positioned cap-like on the posterior surfaces of the endoblasts and mesoteloblast (Fig. 2L).

In frontal sections at $7.5 \mathrm{~h}$, the embryo has elongated in the anterior-posterior axis (Fig. 3A-D). Ypa is in metaphase, dividing laterally (Fig. 3A), while Yal and Yar divide along the anterior-posterior axis (Fig. 3B). Ypp remains in interphase (Fig. 3B); the descendants of this cell are difficult to follow, but likely produce yolk-endoderm cells on the dorsal side. The naupliar mesoderm is still within the epithelial invagination. The endoblasts (El and Er) and primordial germ cell (PGC) are in interphase (Fig. $3 \mathrm{C})$. The primordial mesoteloblast $(\mathrm{M})$ is in interphase on the ventral side (Fig. 3D). At 7.75 h, Ypal and Ypar lie in dorsal frontal sections at the anterior (Fig. 3E), while Yala, Yalp, Yara, Yarp, Yppl, and Yppr are present in more ventral sections (Fig. 3F). These six cells proliferate to yolkendoderm on the dorsal side, and are not traced in any further detail. The primordial cells $\mathrm{El}, \mathrm{Er}$, and $\mathrm{M}$ divide synchronously along an anterior-posterior axis while PGC remains undivided (Fig. $3 \mathrm{G}$ and $\mathrm{H}$ ). The endoblasts divide asymmetrically to produce the smaller descendants e1l and e1r at the anterior and larger endoblasts E11 and E1r at the posterior (Fig. 4A), while M divides to produce the smaller $\mathrm{m} 1$ anteriorly and the larger M1 at the posterior (Fig. 4B).

\subsection{Development from 8 to $10 \mathrm{~h}$}

In frontal sections, by $8 \mathrm{~h}$ the ectoderm begins to invaginate at the boundary between the second antennal and mandibular segments (Fig. 4A and B). The blastopore remains to mark the posterior end of the embryo, while the anterior ectoderm becomes flattened and thickened. Extensive morphogenesis of the ectoderm occurs between 8 and

Fig. 3. S. ingentis development from 7.5 (A-D) to $7.75 \mathrm{~h}(\mathrm{E}-\mathrm{H})$; single frontal optical sections (anterior to left) of samples stained with Sytox Green for DNA. In the $7.5 \mathrm{~h}$ embryo, Ypa is in metaphase of a bilateral division on the dorsal side (A). Deeper into the embryo, Yal and Yar are in metaphase of an anteriorposterior division, while Ypp remains in interphase (B). Further ventrally, El, Er, and PGC remain in interphase (C). On the ventral side, M is in interphase (D). In the $7.75 \mathrm{~h}$ embryo, Ypal and Ypar resulting from Ypa are present in a dorsal section (E). The six descendants of Yal, Yar, and Ypp-Yala, Yalp, Yara, Yarp, Yppl, and Yppr - are present deeper into the embryo (F). The blastopore (Bp) is still open at the posterior. Further ventrally, El and Er divide in anteroposterior plane, while PGC remains in interphase $(\mathrm{G})$. M is present in ventral section (H). Abbreviations: Bp, blastopore; NM, naupliar mesoderm; PGC, primordial germ cell. Scale bar $=50 \mu \mathrm{m}$. 

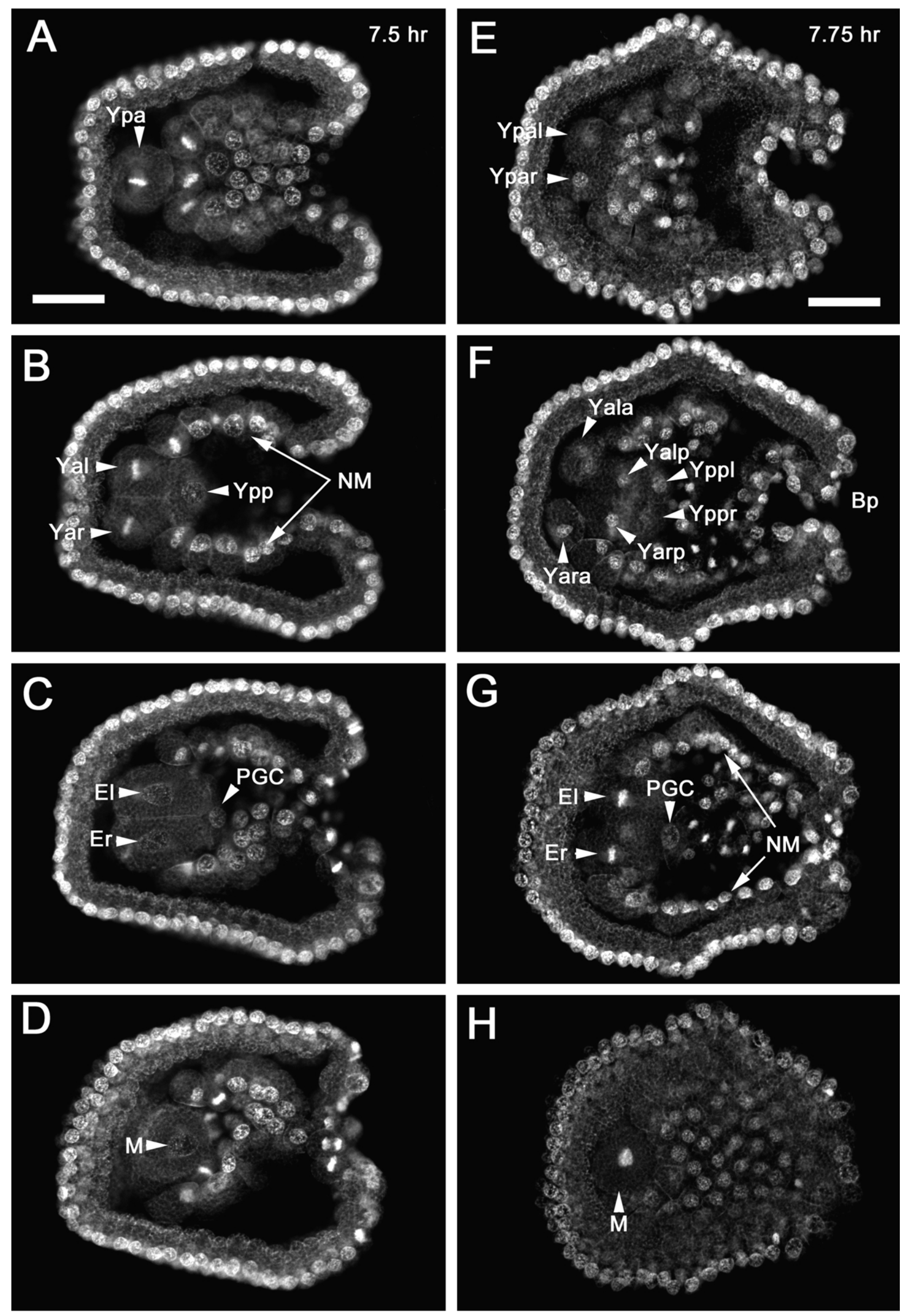
$9 \mathrm{~h}$, marked by specific epithelial invaginations. By $8.75 \mathrm{~h}$ an anterior invagination of neural ectoderm (N) has occurred (Fig. 4C). This pushes the mesendodermal descendants towards the posterior. Another invagination has formed at the boundary between the first (A1) and second (A2) antennal segments. The post-naupliar region has extended to the posterior of the mandibular segment, and contains ectoderm cells with larger nuclei which produce the caudal papilla. The blastopore closes (Fig. 4C and $\mathrm{E})$.

At $8.75 \mathrm{~h}$, the two endoblasts divide again in the anterior-posterior axis to produce smaller descendants e2l and $\mathrm{e} 2 \mathrm{r}$ at the anterior and larger endoblasts E2l and E2r at the posterior (Figs. 4C and 5A). Ventral to the endoblasts, the mesoteloblast also divides in the anterior-posterior axis to form the smaller, anterior $\mathrm{m} 2$ and the larger, posterior M2. The primordial cells refrain from further division for several hours after their second asymmetric division. The PGC remains posterior to the endoblasts and mesoteloblast (Fig. 4C and E). The naupliar mesoderm becomes closely associated with the interior of the ectoderm. By $9.25 \mathrm{~h}$, a composite of several frontal sections shows that M2 lies posterior to E21 and E2r. Individual sections show that M2 lies ventral to the endoblasts, as can be seen in later transverse sections (Fig. 5). Cells posterior and lateral to M2 have highly condensed nuclei. These may be yolkendoderm descendants of Ypp (see Fig. 3B).

\subsection{Development from 10 to $12 \mathrm{~h}$}

By $10 \mathrm{~h}$ the closure of the blastopore can be clearly seen in posterior-most cross sections (Fig. 5A). The cells with large nuclei that will produce the caudal papilla can be seen in an arc around the ventral-lateral sides. The endoblasts and mesoteloblast are present in sections further anterior (Fig. 5B and C). At $10 \mathrm{~h}$, the primordial germ cell divides transversely, for the first time since its formation at the second ME division. The invagination along the dorsal midline separating the paired limb buds can also be seen (Fig. 5C), in contrast to the flattened ventral side. In $11 \mathrm{~h}$ transverse sections, the divided primordial germ cells can be seen within the mandibular segment (Fig. 5D). At the level of the mandible-second antenna boundary, the two endoblasts E2r and E2l are still side-by-side, on top of the mesoteloblast M2 (Fig. 5E). Within the second antenna, the mesoderm descendant $\mathrm{m} 2$ is adjacent to the ventral ectoderm (Fig. 5F).

\subsection{Development from 12 to $16 \mathrm{~h}$}

Frontal sections at $12 \mathrm{~h}$ show the small paired endoderm descendants e 1 and e 2 and E2 endoblasts (Fig. 6A). Ventrally, $\mathrm{m} 2$ and the mesoteloblast M2 are present in the same section (Fig. 6B). Morphogenesis of the ectoderm continues around $13 \mathrm{~h}$, deepening the invaginations between the segments and giving the embryos a less-elongated appearance (Fig. 6C). The neurectoderm invagination is still present at $13 \mathrm{~h}$ but disappears by $14 \mathrm{~h}$ with the internalization of prospective neural cells (Fig. 6C). Proliferation of the naupliar mesoderm and yolk-endoderm continues. From 12 to $15 \mathrm{~h}$, the endoderm cells e1l and e1r lie to the anterior of e2l and e2r (Fig. 6A). Between 13 and $14 \mathrm{~h}$, the endoblasts begin to shift positions from side-by-side laterally to anterior-posterior (Fig. 6A, C, E). The mesoderm cell $\mathrm{m} 1$ lies just anterior of $\mathrm{m} 2$ (Fig. 6B). From 12 to $15 \mathrm{~h}, \mathrm{M} 2$ remains undivided as the largest cell in the embryo on the ventral side (Figs. 6B, D, E and 7A, C). In sagittal optical sections at $15 \mathrm{~h}, \mathrm{M} 2$ is located ventral to the endoblasts (Fig. 6E). Around 15 h, M2 divides laterally to form the two mesoteloblasts MTl and MTr on either side of the midline (Fig. 6G). A number of yolk-endoderm cells with highly condensed nuclei are present laterally and posterior to M2 (Fig. 6G). Naupliar mesoderm extends into the first antennal, second antennal, and mandibular somites (Fig. 6F). The stomadeal invagination begins on the ventral surface, at the junction of A1 and A2 segments, while the limb buds project dorsally (Fig. 6E, F).

By $16 \mathrm{~h}$ the dorsal ectoderm nuclei have become arranged in transverse rows across the embryo, with additional nuclei present around the midline (Fig. 7A, arrowheads). The additional cells appear to proliferate from anterior to posterior. Close inspection reveals that the cells in these rows are elongated in the anterior-posterior direction. At this stage the A1 and A2 segments each have two rows of cells, dividing the segment into anterior and posterior halves. The mandibular segment only has an anterior row of cells at this stage. The endoblasts are present in deeper sections on the dorsal side. The anterior E2 endoblast has divided transversely into E31 and E3r, while the posterior endoblast $\mathrm{E} 2$ has divided in the dorsal-ventral axis to form E3d and E3v (Fig. 7B; E3v is below this section plane and above the one in Fig. 7C). The two mesoteloblasts

Fig. 4. S. ingentis development from 8 (A, B), 8.75 (C, D) and 9.25 h (E, F); single frontal optical sections (anterior to left) of samples stained with Sytox Green for DNA. (A) In an $8 \mathrm{~h}$ embryo, the descendants of El and Er-e11, E1l, e1r, and E1r-are present in dorsal section; the PGC is located at the posterior of the mesendodermal pyramid. (B) In a ventral section, the descendants of $\mathrm{M}-\mathrm{m} 1$ and $\mathrm{M} 1$-are present. The invagination between A2 and Mn is evident. (C) In an $8.75 \mathrm{~h}$ embryo, invaginations between A1 and A2 have also formed. In this dorsal section, the endoblasts E11 and E1r are in anaphase of an anteroposterior division, while PGC remains undivided. The blastopore is still open. (D) In a ventral section, M1 is in metaphase of an anteroposterior division, while its sister $\mathrm{m} 1$ is adjacent to the anterior. (E) In a dorsal frontal section from a $9.25 \mathrm{~h}$ embryo, the PGC is located dorsal to the intersection of the endoblasts and mesoteloblast. (F) In a more ventral section, the endoblasts E21 and E2r and the mesoteloblast M2 are present. Cells with condensed nuclei are probably degenerating (arrowheads). Abbreviations: A1, first antennal segment; A2, second antennal segment; Bp, blastopore; Mn, mandibular segment; N, neural ectoderm; NM, naupliar mesoderm. Scale bars $=50 \mu \mathrm{m}$. 

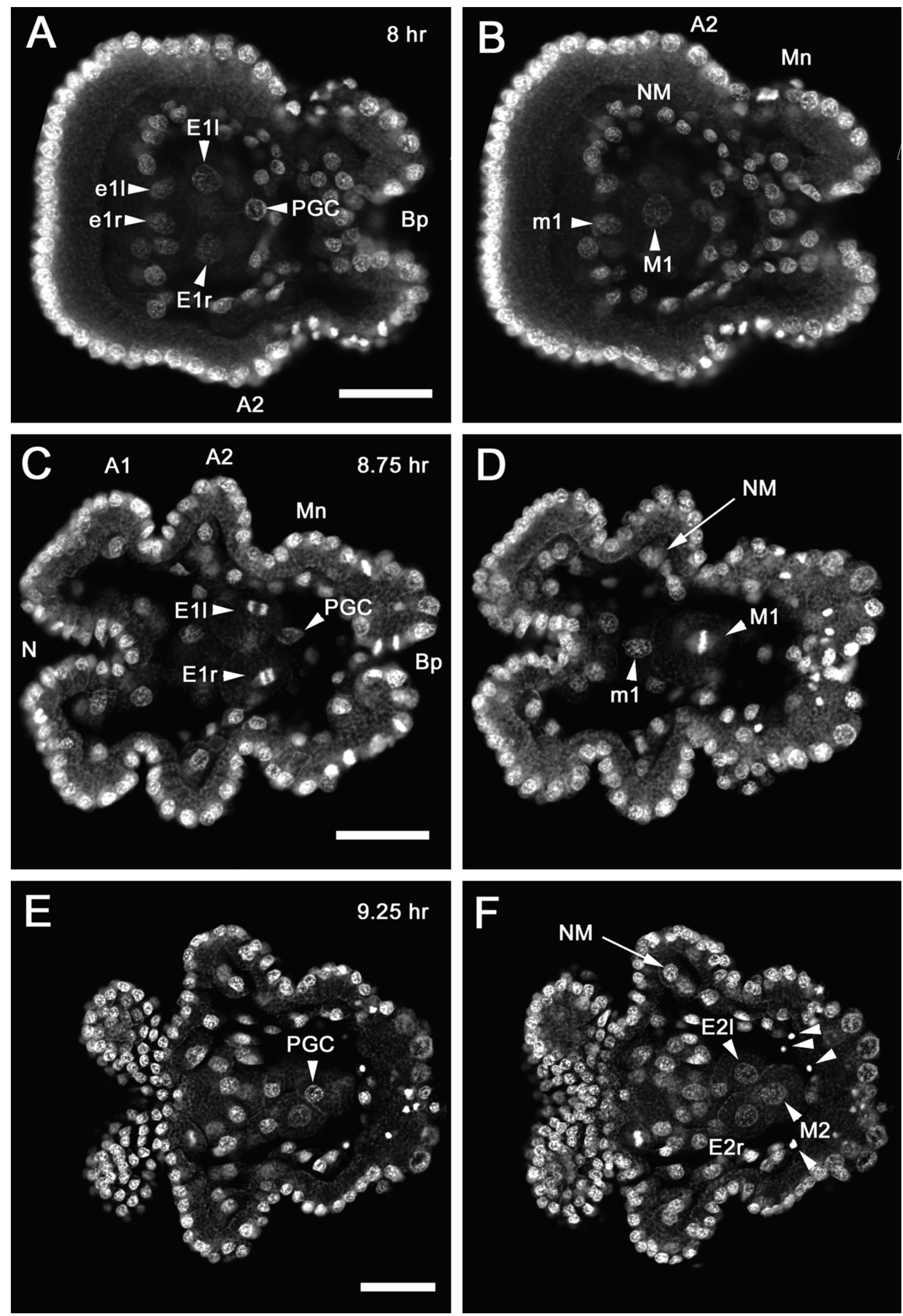

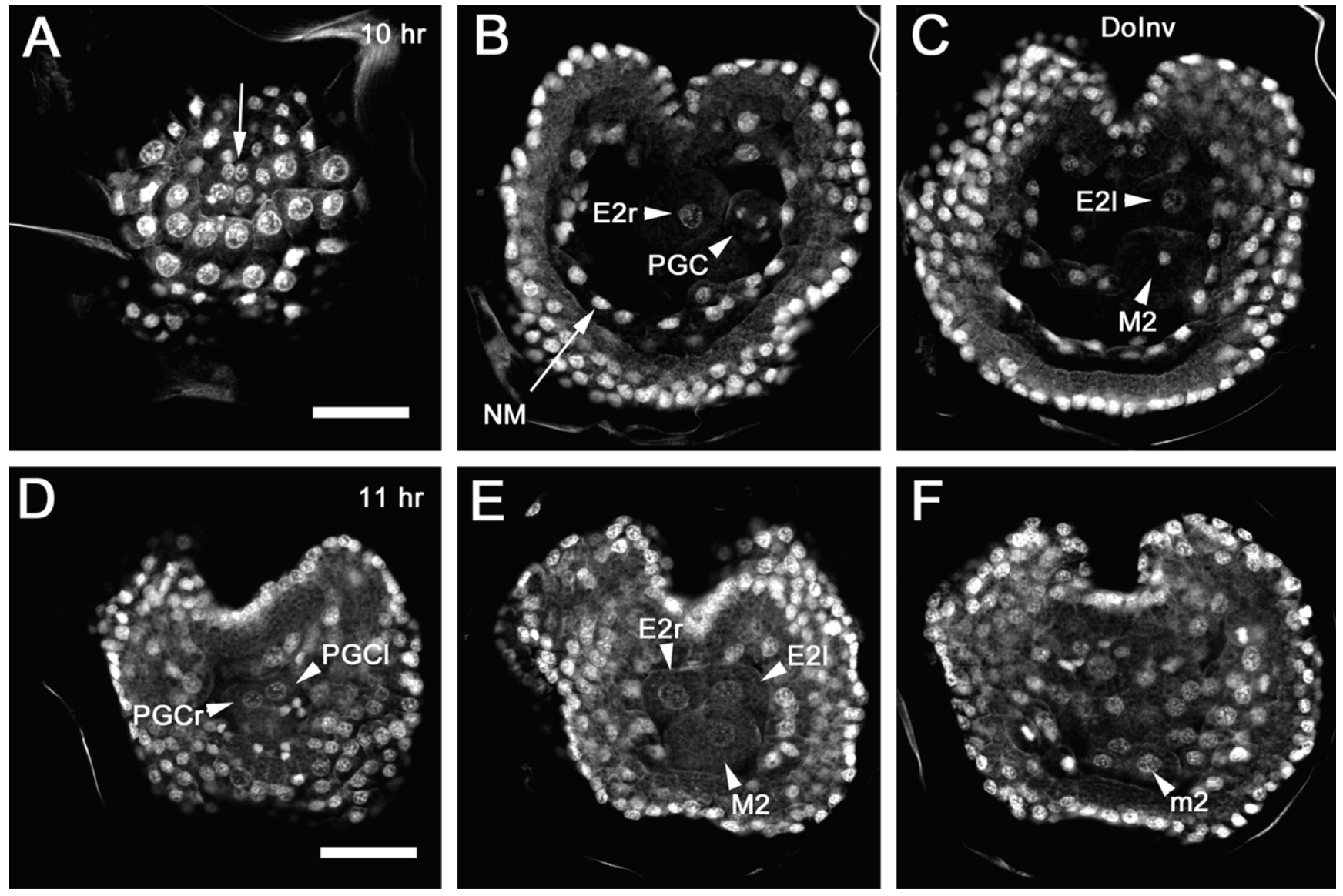

Fig. 5. S. ingentis development at $10(\mathrm{~A}-\mathrm{C})$ and $11 \mathrm{~h}(\mathrm{D}-\mathrm{F})$; transverse optical sections (dorsal on top) of samples stained with Sytox Green for DNA. The shroud around both sets of images is the hatching envelope, which was not removed from these samples. (A) Composite of posterior sections through the postnaupliar region of a $10 \mathrm{~h}$ embryo. Cells have sealed the blastopore (arrow). (B) Section further anterior, through PGC and E2r. (C) Section further anterior, through E21 and M2. (D) Posterior section of an $11 \mathrm{~h}$ embryo, containing the divided primordial germ cells PGCl and PGCr. (E) Section further anterior, through the endoblasts E2r and E21 and the mesoteloblast M2. (F) Section further anterior, through small mesoblast m2. Abbreviations: DoInv, dorsal invagination; NM, Naupliar mesoderm. Scale bar $=50 \mu \mathrm{m}$.

MTl and MTr are present in deeper sections ventrally (Fig. 7C). In sections along the ventral side, large nuclei of prospective ectoteloblasts are present at the boundary between the mandibular segment and the post-naupliar region (Fig. 7D). The highly condensed nuclei of degenerating cells are present inside the ventral ectoderm at the A2 level (DeCe, Fig. 7D), and around the endoblasts and mesoteloblasts.

\subsection{Development from 16 to $24 \mathrm{~h}$}

The further development of the mesoteloblasts can be followed in the hours before hatching. Around $18 \mathrm{~h} \mathrm{MTl}$ and MTr divide in a dorsal-ventral axis (Fig. 7E and F) to produce MTld, MTlv, MTrd, and MTrv (Fig. 7G and H). The endoblasts continue to proliferate dorsal to these cells. At some time between 21 and $24 \mathrm{~h}$, the four mesoteloblasts divide to the final number of eight, in cell divisions around the ventral and lateral sides of the growth zone. The nauplius hatches at $24 \mathrm{~h}$ and the dorsal-ventral orientation can be determined by several characters. The condensed nuclei of the degenerating ectoderm cells and vitellophages are present on the dorsal side of the larva (Fig. 8A); no further evidence of ectodermal rows is apparent. In deeper sections the cell nuclei

Fig. 6. S. ingentis development at 12 (A, B), 14 (C, D) and 15 h (E, F, G); single optical sections of samples stained with Sytox Green for DNA. (A) Dorsal frontal section of embryo at $12 \mathrm{~h}$, showing the paired E2 endoblasts and their descendant pairs e1 and e2. The two PGCs are in division. (B) Ventral frontal section from same embryo showing mesoteloblast M2 and its smaller sister m2. The invagination of neural ectoderm (N) is at the anterior. (C) Dorsal frontal section of $14 \mathrm{~h}$ embryo, with invaginated neural cells (NC) and endoblasts shifting positions to become anteroposterior of each other, and now designated E2a and E2p. (D) Ventral frontal section from same embryo, showing position of M2 within the Mn segment. Cells with condensed nuclei are found lateral to and posterior to M2. (E) Mid-sagittal section of $15 \mathrm{~h}$ embryo, showing position of endoblasts E2a and E2p and anterior endoderm cells (En) on the dorsal interior. (F) Para-sagittal section of same embryo, through the limb buds. Naupliar mesoderm cells are present within the limbs. (G) 15 h embryo, ventral frontal section. M2 is in anaphase of a transverse cell division to form MTl and MTr. Abbreviations: A1, first antennal segment; A2, second antennal segment; En, endoderm cells; Mes, ventral mesoderm cells; Mn, mandibular segment; NC, neural cells; PNR, post-naupliar region. Scale bar $=50 \mu m$. 

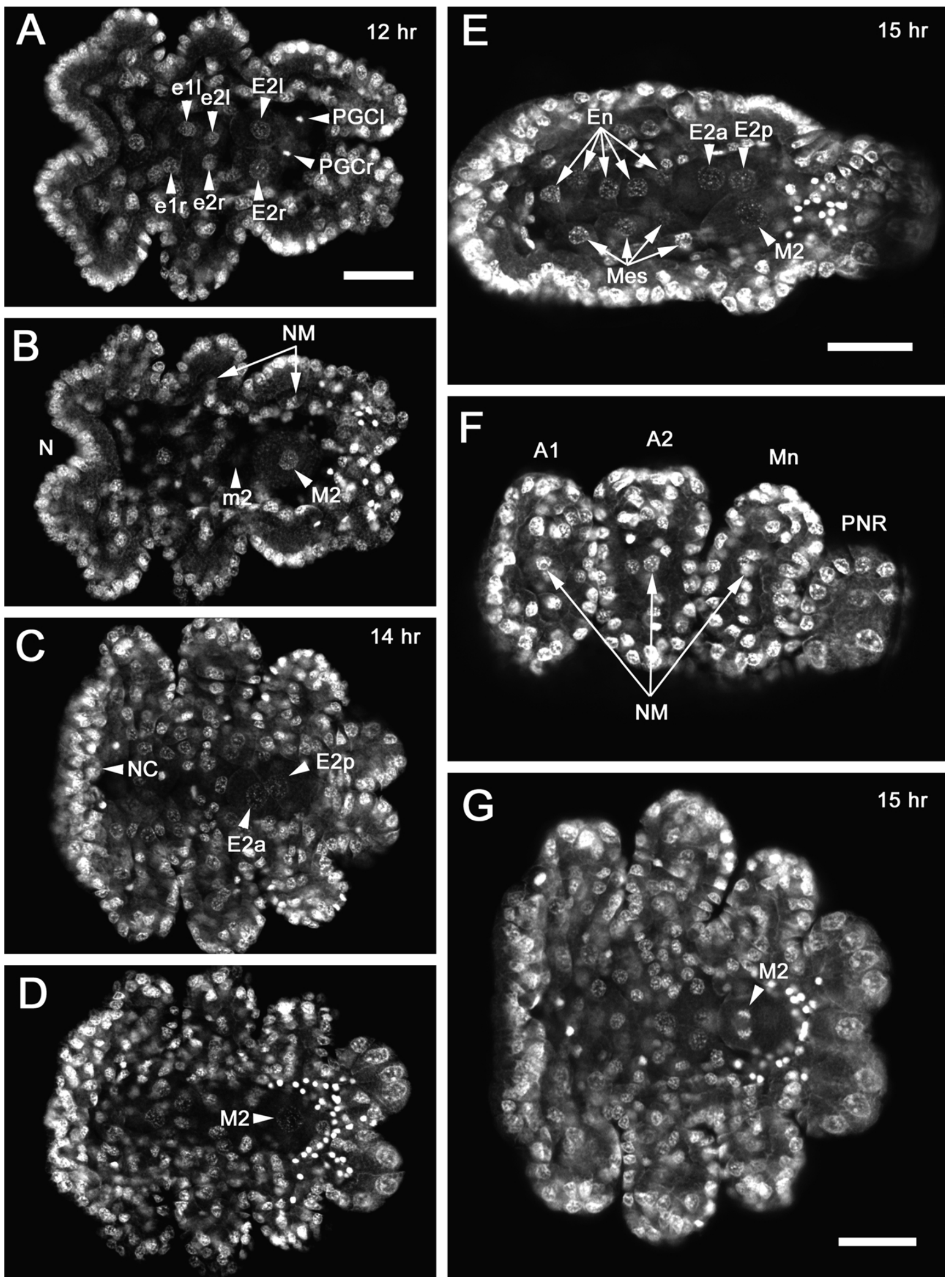
are larger (Fig. 8B and C). The naupliar appendages connect to the body ventrally (Fig. 8C). The stomadeum is present on the ventral side, and the larva is flexed ventrally (Fig. 8D). The teloblastic growth zone is located just anterior to the caudal papilla, flexed towards the ventral side (Fig. 8D).

The numbers of ectoteloblasts and mesoteloblasts can be traced in serial optical sections (Fig. 8E-S). A central ectoteloblast (ET0) is present along the ventral midline in the growth zone (Fig. 8E). Additional ectoteloblasts (ET1ET9) can be traced bilaterally from ET0 in subsequent sections, for a total number of 19. Other ectoderm cells are also present in rows. The ectoderm cells are larger at the dorsal post-naupliar region and degenerate in the dorsal naupliar ectoderm (Fig. 8A and S). Below the ectoteloblasts, the right and left mesoteloblasts MT1 through MT4 can be found on the ventral and lateral sides (Fig. 8J-L, Q, R). A total of eight mesoteloblasts are present at this point.

\section{Discussion}

\subsection{Mesendodermal cell lineage}

The cell lineage of $S$. ingentis through $24 \mathrm{~h}$ postspawning is shown in Fig. 9, as determined from previous studies (Hertzler and Clark, 1992; Hertzler et al., 1994). After the 4-cell stage, the early cleavage divisions occur in a radial orientation, with the $\mathrm{A}$ and $\mathrm{B}$ blastomeres producing ectoderm, C producing ectoderm and naupliar mesoderm, and the vegetal $\mathrm{D}$ blastomere producing ectoderm, naupliar mesoderm and mesendoderm. The two mesendoblasts form at the 32-cell stage. It should be noted that variability occurs in the exact cell lineage, since formation of the naupliar mesoderm is dependent upon their position relative to the mesendoderm (Hertzler and Clark, 1992). In any case, nine prospective naupliar mesoderm cells form around the invaginated mesendoblasts. One possible scenario is outlined in Fig. 9. The fates of the nine naupliar mesoderm founder cells can be followed by their retarded cell division and invagination inside the embryo. The fates of the mesendoderm cells can also be followed by their positions within the embryo and differential rates of cell division.

The development of the mesendoblasts in S. ingentis occurs in a similar way to that described for P. kerathurus (Zilch, 1978, 1979), with small variations. The mesendoblasts form at the 16-cell stage in P. kerathurus, but in both species, they arrest for several cell divisions then resume cell division in a stereotyped way. The orientations of the divisions to four and eight descendants occurs in exactly the same way in both $S$. ingentis and $P$. kerathurus, but the fates of the eight cells differ. In $S$. ingentis, the dorsal mesendoblast produces four yolk-endoderm cells, while the ventral mesendoblast produces two primordial endoblasts (El and Er), one primordial mesoteloblast $(\mathrm{M})$, and one primordial germ cell, PGC (Fig. 10A). In P. kerathurus, the dorsal mesendoblast gives rise to three yolk-endoderm cells and one primordial endoblast, while the ventral mesendoblast produces two yolk-endoderm cells, one mesendoblast and one PGC (Fig. 10B; Zilch, 1979, Fig. 3). This difference in origin of the endoblasts may be real or an artifact of examining static time points. Lineage tracing in vivo will be necessary to unambiguously determine whether the endoblasts derive from the dorsal or the ventral mesendoblast.

\subsection{Endoderm}

In Sicyonia, the dorsal mesendoblast gives rise to yolkendoderm cells, which correspond to the vitellophages described for other crustacean embryos (Anderson, 1973, 1979, 1982). These cells proliferate at the anterior of the mesendodermal pyramid and later spread across the dorsal interior of the embryo, where their nuclei become highly condensed. In P. kerathurus histological sections show that these cells become vacuolated and open to the dorsal surface (Zilch, 1979). The condensed nuclei may be associated either with vacuolization or apoptotic cell degeneration. Some of these cells may later differentiate into the digestive gland, as has been described for other crustaceans (Anderson, 1982). The ectoderm cells overlying the yolkendoderm are likely an embryonic dorsal organ, which assists the yolk-endoderm in supplying nutrients in some crustacean larva (Fioroni, 1980; Martin and Laverack, 1992). The overview of yolk-endoderm development described here provokes some interesting questions, which should be addressed in a future study.

The posterior midgut comes from the endoblasts, teloblastic stem cells that divide toward the posterior, laying down smaller descendants behind them. In Sicyonia, the primordial endoblast (E) forms at the first mesendoderm division, while in P. kerathurus $\mathrm{E}$ forms at the second mesendoderm division. In Sicyonia E divides laterally into $\mathrm{El}$ and $\mathrm{Er}$ at the second mesendoblast division, and lay down

Fig. 7. S. ingentis development at $16 \mathrm{~h}(\mathrm{~A}-\mathrm{D})$ and $18 \mathrm{~h}(\mathrm{E}-\mathrm{H})$; single optical sections of samples stained with Sytox Green for DNA. (A) Dorsal frontal section of $16 \mathrm{~h}$ embryo, showing dorsal projection of limb buds. Trunk cells of the dorsal ectoderm become arranged in rows, two to a segment (arrowheads). (B) Section deeper into the same embryo, showing two descendants of E2a endoblast, E31, E3r and the dorsal descendant of the E2p endoblast, E3d. (C) Section further ventral of the same embryo, showing two M2 descendants, MTl and MTr. (D) Section further ventral, with degenerating cells (DeCe) and positions of ectoteloblasts (arrowheads). (E) Frontal section through $18 \mathrm{~h}$ embryo, showing dorsal-ventral division of MTl and MTr. (F) Section further ventral of same embryo. (G) Different $18 \mathrm{~h}$ embryo, showing mesoteloblasts: MTld and MTrd. The arrowheads indicate the nuclei of these cells, while the cell borders have been outlined using Photoshop. Primordial germ cells (PGCs) remain closely associated with the mesoteloblasts. (H) Section further ventral, showing the mesoteloblasts MTlv and MTrv. Abbreviations: DeCe, degenerating cells; PGCs, primordial germ cells; further abbreviation, see Fig. 6 . Scale bar = 50 $\mu$ m. 

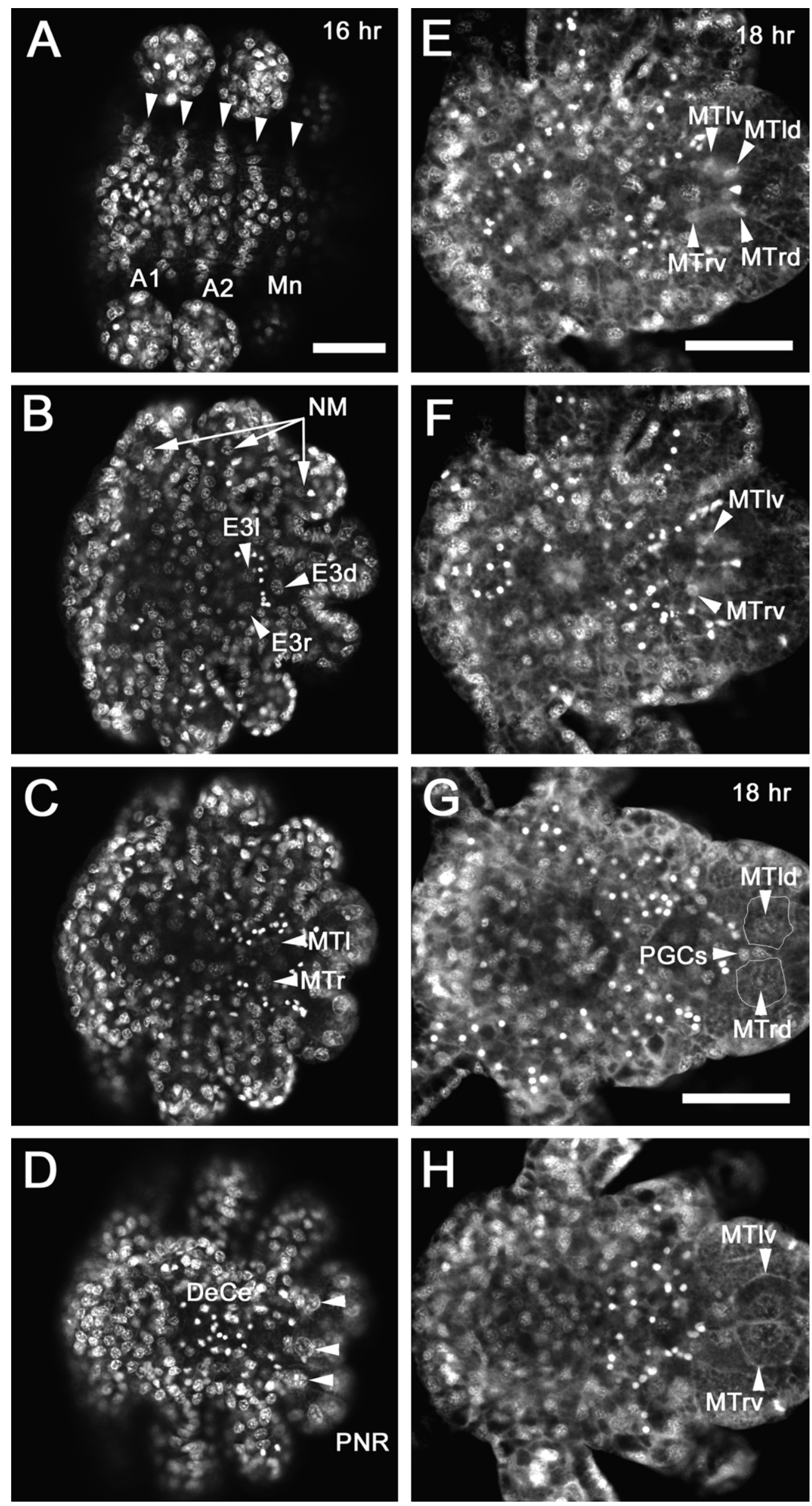
two sets of descendants along the dorsal midline from 7.5 to 9 h. In P. kerathurus the primordial endoblast is reported to remain undivided until the formation of the postnaupliar rudiment (Zilch, 1979). In Sicyonia the endoblasts pause in cell division and rotate to become oriented along the anterior-posterior midline between 12 and $15 \mathrm{~h}$. Between 15 and $16 \mathrm{~h}$, the endoblasts resume division near the growth zone, but no gut tube is present in the nauplius 1 . While the details of primordial endoblast formation may vary in the two dendrobranchiate species examined to date, in both cases endoderm is located dorsal to teloblastic mesoderm. This relationship agrees with the basic crustacean fate map proposed by Anderson (1973).

\subsection{Mesoderm}

The naupliar mesoderm arises from the nine naupliar mesoderm cells (Hertzler and Clark, 1992), which fill the naupliar appendages and gives rise to the limb muscles (Hertzler and Kiernan, unpublished observations). This mesoderm is analogous to the head mesoderm or ectomesoderm of other invertebrates. In the post-naupliar regions, the teloblastic mesoderm, analogous to the endomesoderm of other invertebrates, comes from the primordial mesoteloblast $(\mathrm{M})$, which rises from the ventral mesendoblast and divides towards the posterior. Two rounds of teloblastic cell division produce first $\mathrm{m} 1$ and M1 then $\mathrm{m} 2$ and $\mathrm{M} 2$, in synchrony with the endoblast divisions. M2 remains the largest cell of the embryo, and serves as a useful orientation marker on the ventral side until it divides at $15 \mathrm{~h}$ to form two mesoteloblasts along the midline, MTl and MTr. In P. kerathurus the two mesoteloblasts later divide to form a ring of four then eight mesoteloblasts which become associated with the ectoteloblasts (Zilch, 1978, Fig. 10b,c; Zilch, 1979, Fig. 6e, g) and likely the same pattern occurs in Sicyonia. From the studies in Sicyonia and P. kerathurus, then, the cell lineage of dendrobranchiate mesoteloblasts is proposed as in Fig. 10C. While the formation of eight mesoteloblasts is a characteristic of malacostracan embryos (Dohle and Scholtz, 1997), the precise lineage of these cells varies widely. For example, in Diastylis rathkei (Peracarida, Cumacea), the MT1-MT4 mesoteloblasts have asymmetric cell lineages instead of the direct pattern observed in dendrobranchiate shrimps.

\subsection{Primordial germ cells}

The identification of the primordial germ cell (PGC) in this study should be considered preliminary, since it is based on the circumstantial evidence of morphology and location relative to the mesoderm and endoderm. Zilch identified the PGC in P. kerathurus on the basis of small size, distinct chromosomes within a large nucleus, and posterior location to the endoblasts and mesoteloblast. It would be of great interest to directly identify the PGC by using a probe to the vasa gene product (Mochizuki et al., 2001).

\subsection{Ectoderm morphogenesis and ectoteloblasts}

This study documents the numerous morphogenetic movements that occur during development of the dendrobranchiate nauplius. At $22{ }^{\circ} \mathrm{C}$, these are: anterior-posterior elongation beginning around $7-7.5 \mathrm{~h}$, formation of the $\mathrm{A} 2$ limb bud about $7.75 \mathrm{~h}$, bilateral invaginations between A2 and $\mathrm{Mn}$ at $8 \mathrm{~h}$, bilateral invaginations between $\mathrm{A} 1$ and $\mathrm{A} 2$ and neurectoderm invagination around $8.5 \mathrm{~h}$, blastopore closure around $9 \mathrm{~h}$, invaginations along the dorsal midline that separate the limb buds by $10 \mathrm{~h}$, and an invagination between the mandible and post-naupliar rudiment around $13 \mathrm{~h}$. A caudal papilla forms posterior to the teloblastic growth zone. Preliminary observations indicate that 19 ectoteloblasts may be present in dendrobranchiate nauplii, as in other malacostracan larvae, but a more detailed study is needed. Interesting evidence of segmentation at the cellular level is present in the dorsal ectoderm at $16 \mathrm{~h}$, where lines of cells arrange themselves in anterior and posterior rows within each segment. One wonders if segment polarity genes may be operating at this early stage within the naupliar segments. Later these dorsal ectoderm cells in the naupliar segments degenerate and likely become part of the embryonic dorsal organ, along with the yolk-endoderm.

\section{Conclusions}

The present paper largely confirms and extends the findings of Zilch in a related dendrobranchiate shrimp $P$. kerathurus. The overall cell lineage can now be traced from the egg to the nauplius in $S$. ingentis, providing a descriptive framework for further studies of dendrobranchiate

Fig. 8. S. ingentis nauplius 1, at $24 \mathrm{~h}$; single optical sections of samples stained with Sytox Green for DNA. (A-D) Frontal sections, with anterior to the left. (E-S) Serial frontal sections, every $2.5 \mu \mathrm{m}$, through the post-naupliar region of another nauplius 1. (A) Dorsal section showing numerous degenerating cells in the dorsal interior with condensed nuclei. (B) Deeper section containing cells with typically sized nuclei. (C) Section further ventral, at level where second antennae (A2) and mandibles (Mn) connect to the trunk. The post-naupliar region (PNR) has extended further posterior. (D) Section further ventral, with stomadeum (St) at the A2 segment and appendages projecting ventrally. The teloblastic growth zone (GZ) is present just anterior to the ventrally bent caudal papilla (CP). (E) In a different nauplius 1, the central ectoteloblast (ET0) is present at the ventral midline. The other ectoteloblast pairs, ET1 through ET9 can be traced in a ring in subsequent sections. The MT1 and MT2 mesoteloblast pairs lie above the ectoteloblasts on the ventral side. The MT3 and MT4 mesoteloblast pairs lie medially to the ectoteloblasts on the right and left sides. Abbreviations: CP, caudal papilla; GZ, growth zone; St, stomadeum; further abbreviations, see Fig. 6. Scale bar for A-D $=50 \mu \mathrm{m}, \mathrm{E}-\mathrm{S}=20 \mu \mathrm{m}$. 

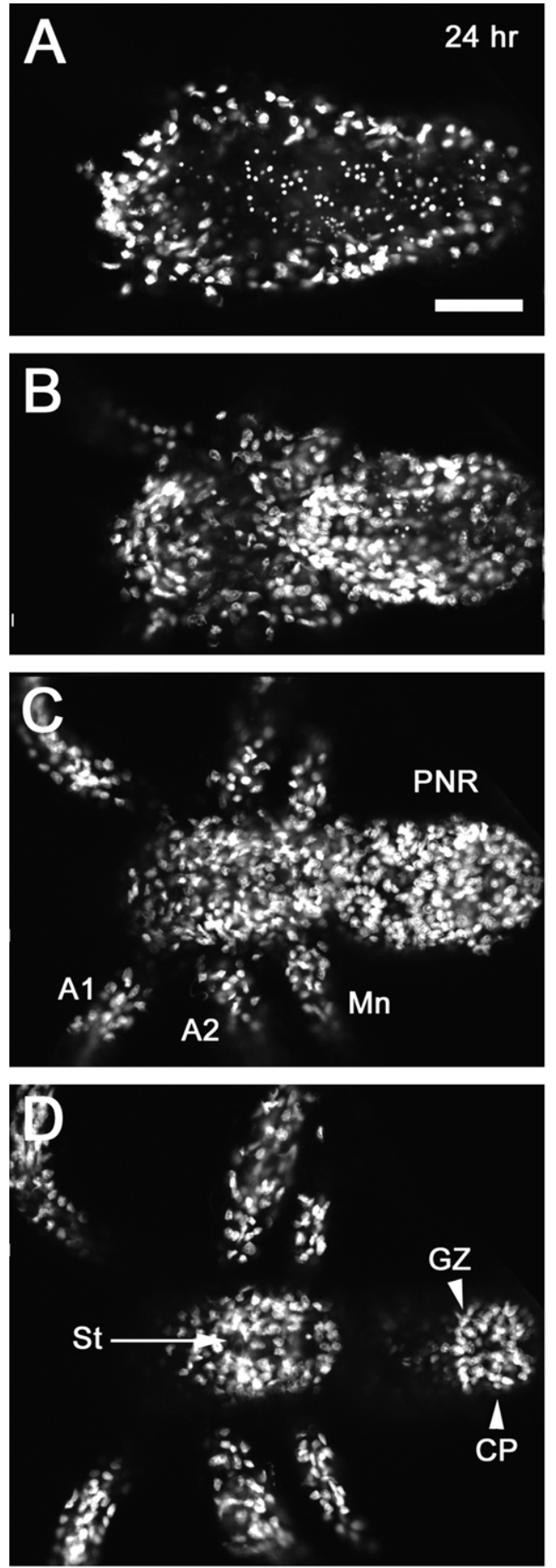
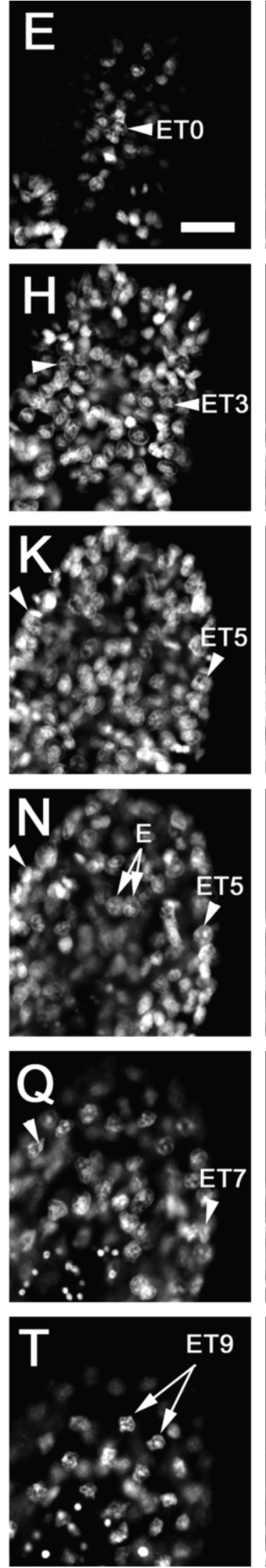
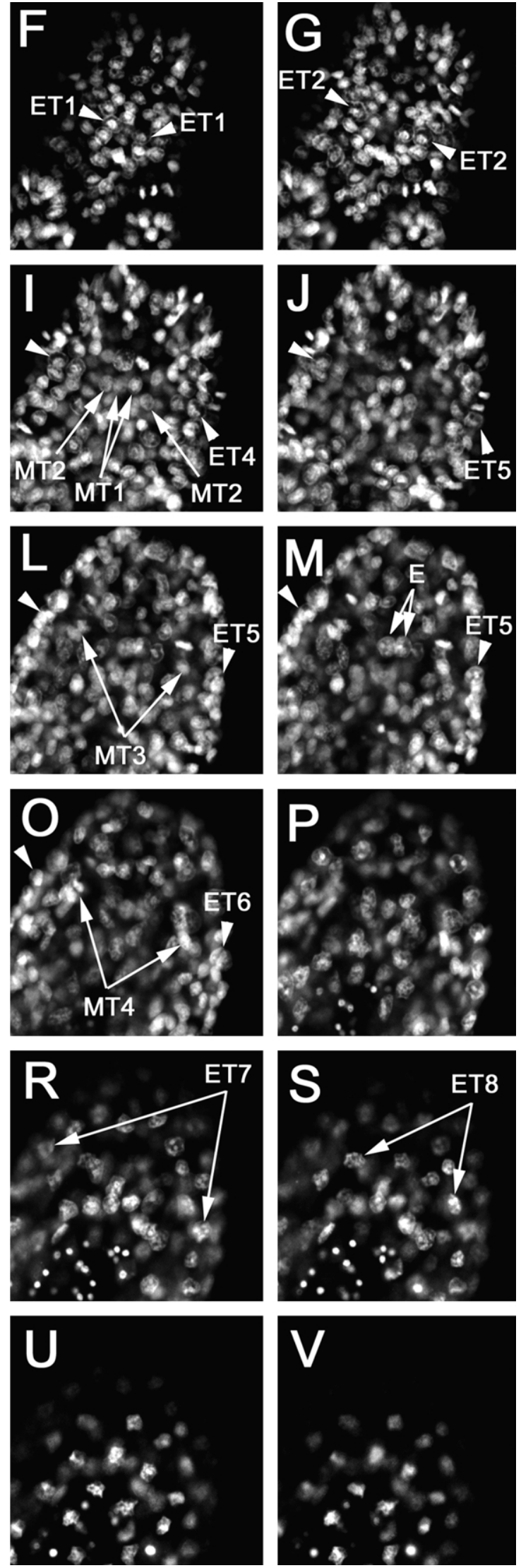


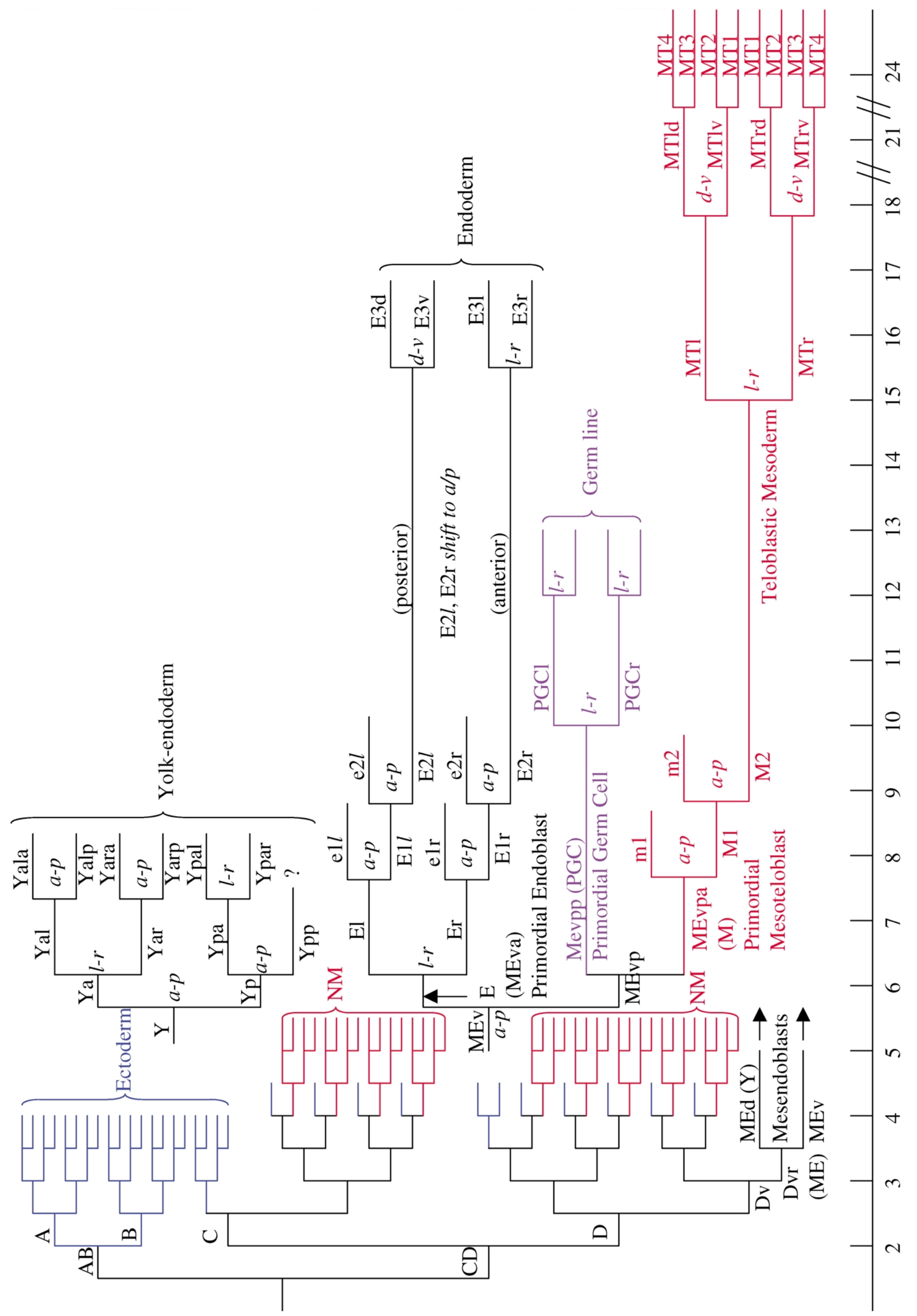


A

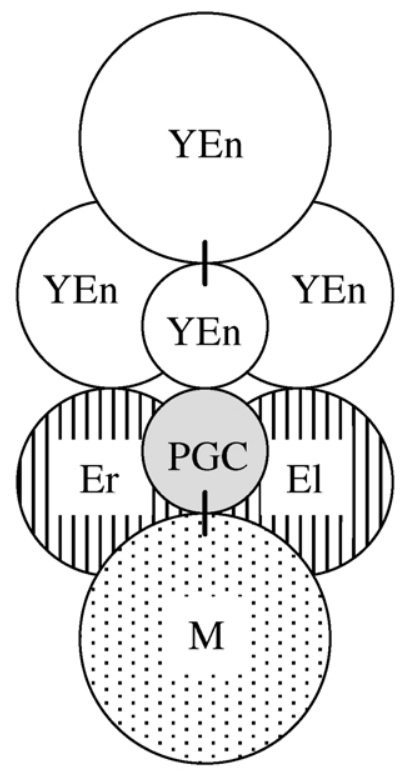

Sicyonia ingentis

B

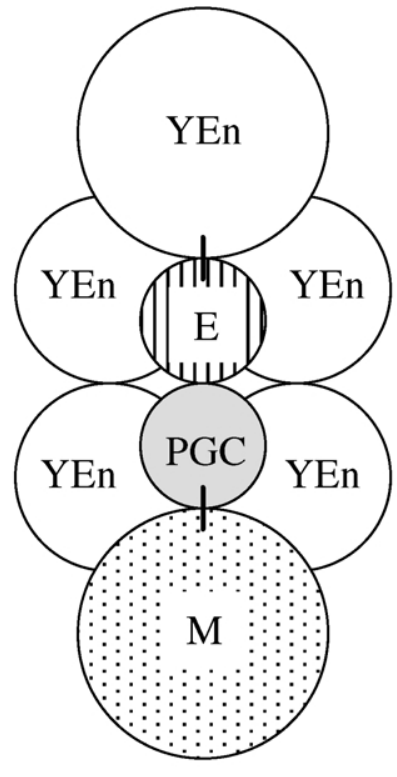

Penaeus kerathurus

C

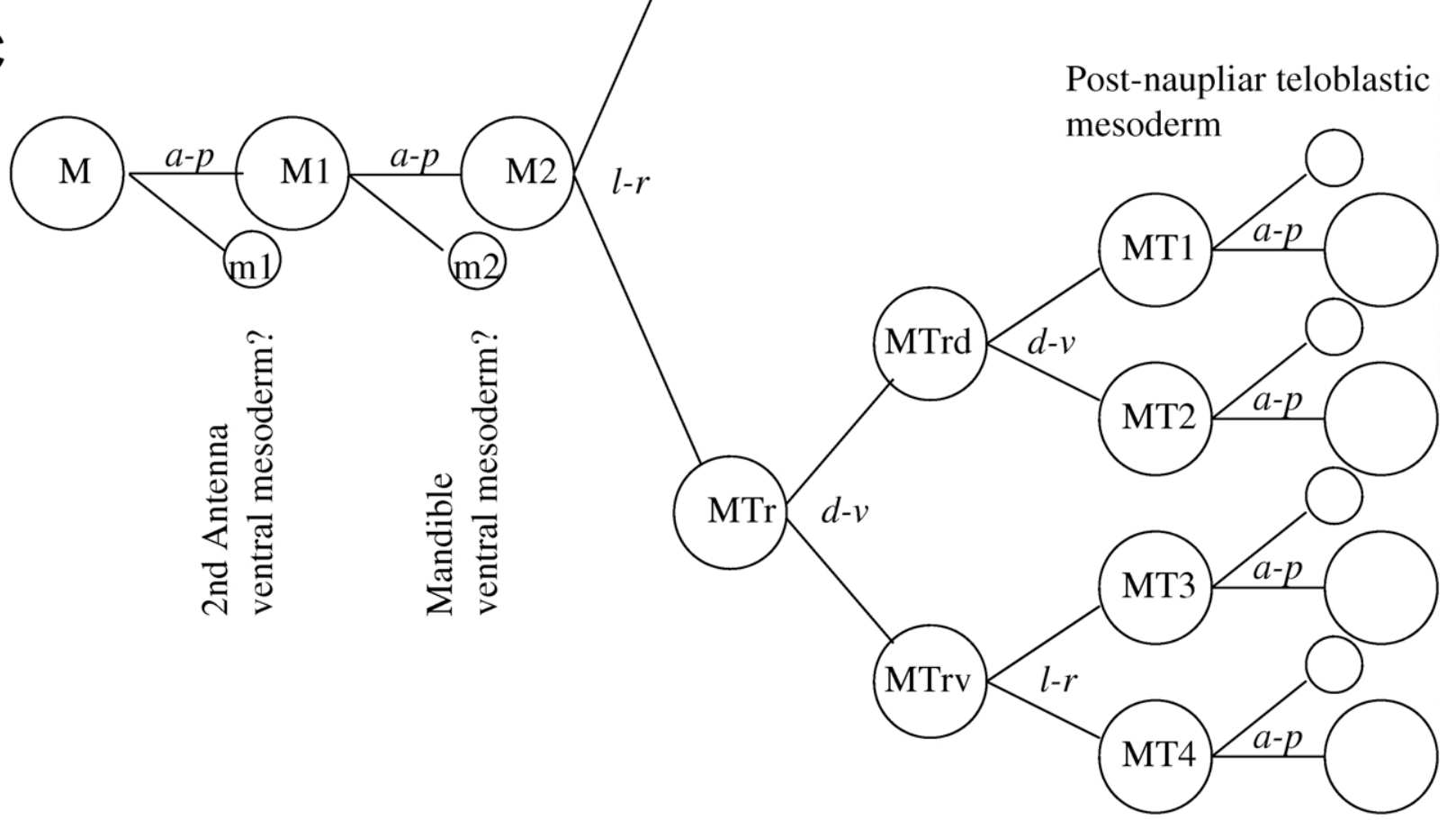

Fig. 10. Cell lineage of mesoteloblasts in dendrobranchiate shrimp. (A) Positions of 8-cell mesendoderm descendants in Sicyonia ingentis, dorsal at top. Y produces all yolk-endoderm cells (YEn), while MEv produces two endoblasts (Er and El), one primordial mesoteloblast (M), and one primordial germ cell (PGC). (B) Positions of 8-cell mesendoderm descendants in P. kerathurus, dorsal at top (Zilch, 1978, 1979). MEd produces three yolk-endoderm cells and one endoblast, while MEv produces two yolk-endoderm cells, one primordial mesoteloblast, and one primordial germ cell. (C) Formation of dendrobranchiate mesoteloblasts, based on this study and Zilch (1978, 1979). M divides through two asymmetric divisions to form M1 and M2 before splitting into the two mesoteloblasts MTr and MTl. Subsequent divisions are shown only for the right side, but are identical on the left. $\mathrm{m} 1 \mathrm{may}$ give rise to ventral mesoderm of A2, while $\mathrm{m} 2$ may produce ventral mesoderm of Mn. Abbreviations: E, El, Er, primordial endoblasts; M, primordial mesoteloblast; MT, mesoteloblast; PGC, primordial germ cell; Yen, yolk-endoderm cells.

Fig. 9. Cell lineage of $S$. ingentis from 0 to $24 \mathrm{~h}$. The scale at the bottom is in hours, with gradations every $1 \mathrm{~h}$ from 1 to $18 \mathrm{~h}$; the division from four to eight mesoteloblasts occurs between 21 and $24 \mathrm{~h}$. The mesendoblasts form at the 32-cell stage. The naupliar mesoderm (NM) founder cells (red lineages) form at the 62-cell stage, and two subsequent cell divisions are shown. Other cells produce ectoderm (blue lineages). These early lineages are variable, since cell fate is position-dependant; one possible tree is shown. The lineage of MEd and MEv is continued from 5.5 to $24 \mathrm{~h}$. MEd (Y) produces only yolk-endoderm cells. MEv produces the definitive endoderm (black lineage), the primordial germ cell line (purple lineage), and the teloblastic mesoderm (red lineage). 
development. This study demonstrates an early dorsalventral arrangement of endoderm and teloblastic mesoderm in dendrobranchiates, starting with the orientation of the two mesendoblasts at the 32-62 cell stage. Thus the dorsalventral axis appears to be specified early on, by the time the two mesendoblasts form at the 32-cell stage (or 16-cell stage in $P$. kerathurus). The position of endoderm dorsal to mesoderm was identified by Anderson as a conserved character among crustaceans (Anderson, 1973, 1979, 1982), and in Sicyonia this can be followed from the founder cells (the mesendoblasts) to their later differentiation. It will be of interest to follow the fates of these tissues during the naupliar stages, when the definitive organogenesis of the midgut and visceral mesoderm occurs.

Some additional embryonic characters common to Malacostraca, as defined by Scholtz and coworkers (Scholtz, 2000; Richter and Scholtz, 2001), are present in dendrobranchiate nauplii, including an antero-ventrally folded caudal papilla, a ring of 19 ectoteloblasts and an embryonic dorsal organ. The question of whether development to a free-swimming nauplius stage in the Dendrobranchiata and Euphausiacea is secondarily derived in the Malacostraca remains open. Recent work places the Euphausiacea within the Peracarida, from its previous position as a basal Eucarida along with the Dendrobranchiata (Jarman et al., 2000; Richter and Scholtz, 2001). Yet free-swimming nauplius larvae are prevalent among more ancestral crustacean taxa (Dahms, 2000). Based on an argument from parsimony, this has led to the suggestion that development of a free-swimming nauplius is secondarily derived in the Dendrobranchiata and Euphausiacea, from a malacostracan ancestor that developed through an eggnauplius (Scholtz, 2000). Thus, the reversion to a freeswimming nauplius may have evolved twice in independent lineages. Perhaps basal crustacean genetic pathways were reactivated in both cases, leading to similar developmental trajectories to a free-swimming nauplius. The resolution of this problem must await further work.

\section{Acknowledgments}

The author is grateful to Gary Martin at Occidental College for use of his lab facilities, and to the crew of the $\mathrm{R} / \mathrm{V}$ Vantuna for shrimp collection. Thanks to Osvaldo Jhonatan Sepulveda Villet and Dan Kiernan, Central Michigan University, for collection of some developmental stages. This work was supported by the Department of Biology and College of Science and Technology at Central Michigan University, State of Michigan/CMU Research Excellence Funds, and CMU President's Research Initiative Funds. Thanks especially to Matthias Gerberding, University of Chicago, for suggestions on improving the manuscript.

\section{References}

Anderson, D.T., 1973. Embryology and Phylogeny in Annelids and Arthropods, Pergaman Press, Oxford.

Anderson, D.T., 1979. Embryos, fate maps, and the phylogeny of arthropods. In: Gupta, A.P., (Ed.), Arthropod Phylogeny, Van Nostrand Reinhold Co, New York, pp. 59-105.

Anderson, D.T., 1982. Embryology. In: Abele, L.G., (Ed.), The Biology of the Crustacea, vol. 2. Academic Press, New York, pp. 1-41.

Baldwin, J.D., Bass, A.L., Bowen, B.W., Clark, W.H., 1998. Molecular phylogeny and biogeography of the marine shrimp Penaeus. Molecular Phylogenetics and Evolution 10, 399-407.

Bowman, T.E., Abele, L.G., 1982. Classification of the Recent Crustacea. In: Abele, G., (Ed.), The Biology of the Crustacea, vol. 1. Academic Press, New York, pp. 1-27.

Brooks, W.K., 1882. Lucifer, a study in morphology. Philosophical Transactions of the Royal Society of London B 173, 57-137.

Brusca, R.C., Brusca, G.J., 1990. Invertebrates, Sinauer Associates, Sunderland, MA.

Burkenroad, M.D., 1983. Natural classification of Dendrobranchiata, with a key to recent genera. In: Schram, F.R., (Ed.), Crustacean Phylogeny, Crustacean Issues 1, A.A. Balkema, Rotterdam, pp. 279-290.

Dahms, H.-U., 2000. Phylogenetic implications of the crustacean nauplius. Hydrobiologia 417, 91-99.

Dall, W., Hill, B.J., Rothlisberg, P.C., Sharples, D.J., 1990. The Biology of the Penaeidae, Academic Press, London.

Dohle, W., Scholtz, G., 1997. How far does cell lineage influence cell fate specification in crustacean embryos? Seminars in Cell and Developmental Biology 8, 379-390.

Fioroni, P., 1980. Das Dorsalorgan der Arthropoden unter besonderer Berucksichtigung der malakostraken Krebse-eine vergleichend embryologische Übersicht. Zoologische Jahrbücher (Anatomie) 104, 425-465.

Gilbert, S.F., 1997. Arthropods: the crustaceans, spiders, and myriapods. In: Gilbert, S.F., Raunio, A.M. (Eds.), Embryology: Constructing the Organism, Sinauer Associates, Inc, Sunderland, MA, pp. 237-257.

Hertzler, P.L., Clark, W.H. Jr., 1992. Cleavage and gastrulation in the shrimp Sicyonia ingentis: invagination is accompanied by oriented cell division. Development 116, 127-140.

Hertzler, P.L., Wang, S.W., Clark, W.H. Jr., 1994. Mesendoderm cell and archenteron formation in isolated blastomeres from the shrimp Sicyonia ingentis. Developmental Biology 164, 333-344.

Jarman, S.N., Nicol, S., Elliott, N.G., McMinn, A., 2000. 28S rDNA evolution in the Eumalacostraca and the phylogenetic position of krill. Molecular Phylogenetics and Evolution 17, 26-36.

Kajishima, T., 1951. Development of isolated blastomeres of Penaeus japonicus. Zoological Magazine 60, 258-262.

Maggioni, R., Rogers, A.D., Maclean, N., D’Incao, F., 2001. Molecular phylogeny of Western Atlantic Farfantepenaeus and Litopenaeus shrimp based on mitochondrial 16S partial sequences. Molecular Phylogenetics and Evolution 18, 66-73.

Martin, J.W., Laverack, M.S., 1992. On the distribution of the crustacean dorsal organ. Acta Zoologica (Stockholm) 73, 357-368.

Mochizuki, K., Nishimiya-Fujisawa, C., Fujisawa, T., 2001. Universal occurrence of the vasa-related genes among metazoans and their germline expression in Hydra. Development, Genes and Evolution 211, 299-308.

Perez-Farfante, I., Kensley, B.F., 1997. Peaneoid and Sergestoid shrimps and prawns of the world: keys and diagnoses for the families and genera. Mémoires du Museum National d'Histoire Naturelle, Paris 175, $1-233$.

Pillai, M.C., Griffin, F.J., Clark, W.H. Jr., 1988. Induced spawning of the decapod crustacean shrimp Sicyonia ingentis. Biological Bulletin 174, $181-185$.

Richter, S., Scholtz, G., 2001. Phylogenetic analysis of the Malacostraca 
(Crustacea). Journal of Zoological Systematics and Evolution Research $39,113-136$.

Scholtz, G., 2000. Evolution of the nauplius stage in malacostracan crustaceans. Journal of Zoological Systematics and Evolution Research $38,175-187$

Shiino, S.M., 1957. Arthropoda. In: Kumé, M., Dan, K. (Eds.), Invertebrate embryology, Bai Fu Kan Press, Tokyo, Republished in 1988 by Republished Garland Publishing, Inc., New York. pp. $333-484$.

Taube, E., 1909. Beiträge zur Entwicklungsgeschichte der Euphausiden.
I. Die Furchung des Eis bis zur Gastrulation. Zeitschrift für Wissenschaftliche Zoologie 92, 427-464.

Taube, E., 1915. Beiträge zur Entwicklungsgeschichte der Euphausiden. II. Von der Gastrula bis zum Furciliastadium. Zeitshrift für Wissenschaftliche Zoologie 114, 577-656.

Zilch, R., 1978. Embryologische Untersuchungen an der holoblastischen Ontogenese von Penaeus trisulcatus Leach (Crustacea, Decapoda). Zoomorphologie 90, 67-100.

Zilch, R., 1979. Cell lineage in arthropods? Journal of Zoological Systematics and Evolution Research 1, 19-41. 